\title{
Do energy scenarios pay sufficient attention to the environment? Lessons from the UK to support improved policy outcomes
}

Tara Hooper $^{* 1,2}$, Melanie C. Austen ${ }^{1,2}$, Nicola Beaumont ${ }^{1,2}$, Philip Heptonstall ${ }^{3,2}$, Robert A. Holland ${ }^{4,2}$, Ioanna Ketsopoulou ${ }^{2}$, Gail Taylor ${ }^{4,2}$, Jim Watson $^{2}$, and Mark Winskel ${ }^{5,2}$

${ }^{1}$ Plymouth Marine Laboratory, Prospect Place, The Hoe, Plymouth, PL1 3DH, UK

${ }^{2}$ UK Energy Research Centre, 58 Princes Gate, London SW7 2PG, UK

${ }^{3}$ Centre for Environmental Policy, Imperial College London, London, SW7 2AZ, UK

${ }^{4}$ Biological Sciences, University of Southampton, Life Sciences Building (B85), Highfield Campus, Southampton, SO17 1BJ, UK

${ }^{5}$ School of Social and Political Science, University of Edinburgh, Edinburgh EH1 1LZ

* corresponding author: tarh@pml.ac.uk

\begin{abstract}
Scenario development is widely used to support the formation of energy policy, but many energy scenarios consider environmental interactions only in terms of climate change. We suggest that efforts to develop more holistic energy pathways, going beyond post hoc analysis of environmental and social implications, can usefully draw on environmental scenarios. A detailed content analysis of UK energy and environmental scenarios was therefore undertaken, with energy scenarios selected on the basis that they were recent, had a direct link to energy policy, and covered a range of scenario types. The energy scenarios rarely considered societal drivers beyond decarbonisation and focused on quantifiable parameters such as GDP, while the environmental scenarios provided a richer narrative on human behaviour and social change. As socio-economic issues remain fundamental to the success of energy policies, this is a key area which should be better addressed within energy scenarios. The environmental impacts of energy scenarios were rarely considered, but could have a significant bearing on the likelihood of pathway outcomes being realised. Fuller evaluation of the environmental interactions of energy systems is therefore required. Although the analysis focuses on the UK, some international scenarios show similar limitations, suggesting that the conclusions are more widely applicable.
\end{abstract}




\section{Keywords}

Energy; Environment; Scenarios; Policy; UK

\section{Introduction}

There is growing international momentum to reduce carbon emissions and mitigate the effects of climate change, with the Paris Agreement enshrining the aspiration to limit global temperature increase to $1.5^{\circ} \mathrm{C}$ above pre-industrial levels (UNFCC, 2015). In parallel, the Intergovernmental Platform for Biodiversity and Ecosystem Services (IPBES) and initiatives such as the Aichi Biodiversity Targets (Convention on Biological Diversity, 2012) and the Millennium Ecosystem Assessment (MEA, 2005) seek to mainstream the importance of biodiversity and ecosystem services within policy at international, national and regional levels. The UK has been a global leader across these domains by establishing a legally binding set of carbon budgets and targets (Committee on Climate Change, 2015a), and in the integration of ecosystem services within policy development informed by the UK National Ecosystem Assessment (2011). As such we focus on the UK as an exemplar to explore integration of energy and environmental scenarios in policy development. Therefore, whilst the focus of this paper is on the UK, there is an important opportunity to learn lessons for scenarios that focus on other countries.

National policy decisions are commonly informed by energy scenarios (Berntsen and Trutnevyte, 2017), and this has been particularly the case in the UK over the past decade. The 2008 Climate Change Act established a long-term target for the decarbonisation of the UK economy, to be achieved by a set of diminishing five-year 'carbon budgets' between 2008 and 2050. This statutory combination of long-term change and step-wise progression has encouraged the proliferation of quantitative energy scenarios in the UK since 2008, with energy policy development informed particularly by scenarios produced by the government's official advisory body, the UK Committee on Climate Change (CCC) (Winskel, 2016). 
Scenarios are defined as a postulated sequence or development of events, and can be either explorative (considering the evolution of possible futures from a pre-set storyline) or normative (exploring ways to achieve a specific future objective), with intermediate approaches also possible (van Vuuren et al., 2015). Scenario development allows for the consideration of alternative futures and their evolution from the present, and thus provides insights into the decisions required in the nearterm (Hughes, 2009). UK energy scenarios typically focus on decarbonisation, energy security, investment requirements and affordability (the 'pillars' of the energy trilemma) (DECC, 2014); they consider the whole energy system or discrete elements of it; they have been commissioned by academia, industry, the Government and Non-Governmental Organisations; and they use qualitative and quantitative approaches (Trutnevyte et al., 2016; McDowell et al., 2014; Holland et al, 2016a, Skea et al., 2011). Fulfilling these combined objectives set by multiple actors presents an enormous challenge, not least as there is considerable uncertainty about energy futures, particularly for the longer-term time horizons to 2050 and beyond.

However, despite this range, almost all energy scenarios considered in recent reviews (Trutnevyte et al., 2016; McDowell et al., 2014; Holland et al, 2016a) have in common (by the nature of the questions they have been conceived to address) a relatively narrow consideration of environmental consequences beyond those associated with greenhouse gas emissions. The post hoc evaluation of the environmental implications of energy pathways does take place both in the UK and internationally, for example for pollutant emissions and water use (Howard et al., 2011), in terms of effects on biodiversity (BIO by Deloitte, IEEP and CEH, 2014) and through Life Cycle Assessment (Hammond et al., 2013). However, this is rarely an integral component of the scenario development itself. Limitation of energy scenarios to considering one environmental externality, greenhouse gas emissions, seems short-sighted especially in light of other legal obligations and international commitments on, for example, biodiversity.

Also, failure to consider the broader environmental consequences of energy futures brings the risk that the pathways described may have negative environmental consequences or may miss opportunities to 
deliver ancillary environmental and social benefits (Holland et al., 2016a). Thus, the credibility of the pathways produced may be undermined, the underlying assumptions of the energy models may be brought into question, or pathways may be generated that are unrealistic in practice. A recent example of the unintended impacts of narrowly defined, decarbonisation-focused energy policy was the UK Government's prioritisation of carbon emissions reduction as the primary mechanism for sustainable mobility, which incentivised the purchase of diesel vehicles and led to increases in air pollution (Brand, 2016, Skeete, 2017).

A further limitation of post hoc assessment is that the analysis is almost invariably undertaken later, and by a separate agency. This means that the two-way interactions between energy systems and environmental systems are not taken fully into account in such cases; post hoc analysis considers the impact of energy systems on the environment but not how environmental factors enable or constrain the future development of energy systems. Post hoc analysis many not be comprehensive and is likely to have weaker policy impact than a more holistic approach in which wider environmental and social concerns are addressed directly during the development of energy pathways..

An 'energy only' approach may also not reflect emerging governance practices. Already within the UK, the Government's industrial strategy green paper (HM Government, 2017) is explicit on the need to reconsider its approach to the energy 'trilemma' and to place greater emphasis on the affordability of energy and the economic growth potential of the low carbon sector in developing its policies for addressing climate change. In addition, UK energy policy does not reflect the rise of integrative and holistic policy and research framings which bridge across food, water and climate (Cairns and Krzywoszynska, 2016). This concept of nexus thinking has emerged as a means of building synergies across different sectors and transcending traditional policy silos (Sharmina et al., 2016). Water, energy, and food have been at the core of nexus concepts (e.g. United Nations, 2014), with increasing calls for wider environmental and socio-ecological considerations to be incorporated within the paradigm (de Grenade et al., 2016). 
Closer integration of energy and environmental scenarios has been proposed as one route to ensuring that energy strategies take account of broader environmental, economic and social objectives (Holland et al., 2016b). In order to explore the potential of such integration in the development of energy policy, we have undertaken a detailed analysis of UK energy and environment scenarios encompassing a broad range from those based on quantitative modelling through to qualitative studies. We have focussed primarily on the development of 'whole systems' pathways, as these are most appropriate in the context of the development of national energy policy. We examine the key features of the scenarios and assess their commonalities, differences and the consistency between them. In particular, we discuss the lessons that can be learned from the environmental scenarios, and conclude with recommendations for the development of future energy scenarios.

\section{Method}

\subsection{Scenario selection}

The analysis considered eight scenario sets: three of which explored the possible response of the natural environment to broad societal change, while five focused on the future energy landscape (Table 1). A 'scenario set' is defined here as the overarching study, within which there may be multiple individual scenarios. There are many scenario sets that propose relevant scenarios; Holland et al. (2016a), for example, identified six environmental and 13 energy scenario sets for the UK. In this analysis, only a subset of these were considered in order to permit detailed assessment to be carried out. 
Table 1. Summary of the main characteristics of the scenario sets used in the analysis

\begin{tabular}{|c|c|c|c|c|c|c|c|c|c|}
\hline Group & $\begin{array}{l}\text { Policy } \\
\text { sector }\end{array}$ & Scenario set & $\begin{array}{l}\text { Scenario set } \\
\text { short title }^{\mathrm{a}}\end{array}$ & $\begin{array}{c}\text { Date } \\
\text { produced }\end{array}$ & Aim & $\begin{array}{l}\text { Timeframe(s) } \\
\text { considered }\end{array}$ & $\begin{array}{c}\text { Main } \\
\text { approach }\end{array}$ & $\begin{array}{l}\text { Number of } \\
\text { scenarios }\end{array}$ & Reference \\
\hline Environment & Academic & $\begin{array}{l}\text { UK National } \\
\text { Ecosystem } \\
\text { Assessment }\end{array}$ & UK NEA & 2011 & $\begin{array}{l}\text { To gather insight into how ecosystem } \\
\text { services and human well-being might change }\end{array}$ & 2060 & Qualitative & 6 & $\begin{array}{l}\text { Haines- } \\
\text { Young et } \\
\text { al., } 2011\end{array}$ \\
\hline Environment & Academic & $\begin{array}{l}\text { UK Climate } \\
\text { Impacts Programme }\end{array}$ & UK CIP & 2001 & $\begin{array}{l}\text { To reflect upon possible alternative futures } \\
\ldots \text { in the context of climate change impacts. }\end{array}$ & $2020 \mathrm{~s} / 2050 \mathrm{~s}$ & Qualitative & 8 & $\begin{array}{l}\text { UK Climate } \\
\text { Impacts } \\
\text { Programme, } \\
2001\end{array}$ \\
\hline Environment & $\begin{array}{l}\text { Government } \\
\text { advisor }\end{array}$ & $\begin{array}{l}\text { England's Natural } \\
\text { Environment in } \\
2060\end{array}$ & $\begin{array}{l}\text { Natural } \\
\text { England }\end{array}$ & 2009 & $\begin{array}{l}\text { To explore a range of plausible futures to } \\
\text { help anticipate and appreciate challenges and } \\
\text { opportunities facing the natural environment }\end{array}$ & 2060 & Qualitative & 4 & $\begin{array}{l}\text { Creedy et } \\
\text { al., } 2009\end{array}$ \\
\hline Energy & $\begin{array}{l}\text { Government } \\
\text { advisor }\end{array}$ & $\begin{array}{l}\text { The Fifth Carbon } \\
\text { Budget }\end{array}$ & $\begin{array}{l}\text { Fifth Carbon } \\
\text { Budget }\end{array}$ & 2015 & $\begin{array}{l}\text { To keep the costs of tackling climate change } \\
\text { to a minimum }\end{array}$ & $2028-2032$ & Quantitative & 17 & $\begin{array}{l}\text { Committee } \\
\text { on Climate } \\
\text { Change, } \\
\text { 2015a,b }\end{array}$ \\
\hline Energy & Industry & $\begin{array}{l}\text { National Grid } \\
\text { Future Energy } \\
\text { Scenarios }\end{array}$ & $\begin{array}{l}\text { National } \\
\text { Grid }\end{array}$ & 2015 & $\begin{array}{l}\text { To explore how this complex energy } \\
\text { landscape is changing and analyse how the } \\
\text { future might play out }\end{array}$ & $2030 / 2050$ & Quantitative & 8 & $\begin{array}{l}\text { National } \\
\text { Grid, } 2015\end{array}$ \\
\hline Energy & Academic & $\begin{array}{l}\text { The future role of } \\
\text { natural gas in the } \\
\text { UK }\end{array}$ & UKERC Gas & 2015 & $\begin{array}{l}\text { To explore what overall role natural gas } \\
\text { could play in a future transition to a low- } \\
\text { carbon UK }\end{array}$ & 2050 & Quantitative & 8 & $\begin{array}{l}\text { McGlade et } \\
\text { al., } 2016\end{array}$ \\
\hline Energy & Academic & $\begin{array}{l}\text { Challenging Lock- } \\
\text { in through Urban } \\
\text { Energy Systems }\end{array}$ & CLUES & 2012 & $\begin{array}{l}\text { To consider what the future of energy might } \\
\text { look like }\end{array}$ & 2050 & Qualitative & 2 & $\begin{array}{l}\text { Sherriff and } \\
\text { Turcu. } 2012\end{array}$ \\
\hline Energy & NGO & $\begin{array}{l}\text { The RSPB's } 2050 \\
\text { energy vision }\end{array}$ & RSPB & 2016 & $\begin{array}{l}\text { To assess how the UK can transition to a low } \\
\text { carbon energy system, and deliver the } 80 \% \\
\text { emissions reduction target, whilst limiting } \\
\text { negative impacts on sensitive species and } \\
\text { habitats }\end{array}$ & 2050 & Quantitative & 3 & $\begin{array}{l}\text { Roddis et } \\
\text { al., } 2016\end{array}$ \\
\hline
\end{tabular}

${ }^{a}$ by which the scenario set will be referred to in this study 
Three environmental scenario sets were selected, those prepared by the UK National Ecosystem Assessment (UKNEA; Haines-Young et al., 2011), UK Climate Impacts Programme (2001), and Natural England (Creedy et al., 2009). These were chosen because they scored most highly in Holland et al. (2016a) in terms of the level of detail of their coverage of environmental issues and energy systems, as well as the broader definition, scope and robustness of the approach (with the most robust approaches defined as those with a clearly documented method likely to produce rigorous outputs and representing best practice).

The priority in selecting UK scenario sets for energy was to include the most recent scenarios, and particularly those with a direct link to UK policy development. Within this overarching aim, additional criteria were to include a range of scenario types, and to ensure representation from three different sectors whose work can influence energy policy: agencies who advise the UK Government directly, the energy industry, and academia. The scenarios selected to represent these three sectors were: i) the Fifth Carbon Budget (Committee on Climate Change, 2015a,b) produced by the UK's statutory advisor to government on carbon emissions in relation to the possible means of achieving legally binding targets; ii) the National Grid (2015) scenario set developed by the national system operator to consider the future demands on electricity and gas transmission networks; and iii) scenarios produced by the UK's national academic centre for energy research (the UK Energy Research Centre) that explore options for the future of natural gas (McGlade et al., 2016).

Holland et al. (2016a) identified additional UK energy scenarios (ETI, 2015; Tran et al., 2014; Ekins et al., 2013; Foxon and Pearson, 2013; DECC, 2011; Ofgem, 2009; and Foresight, 2008). These were not selected for this analysis, as they generally pre-dated our chosen scenario sets. ETI (2015) is also a recent scenario set produced by the industry sector, but the National Grid scenarios were selected in preference due to their more comprehensive coverage of the whole energy system and their closer links to investment decision making in the UK energy sector. 
A further objective of the analysis presented in this paper was to consider a broad range of energy scenario types, and so two further sets of scenarios have been analysed. The three scenario sets described above (the Fifth Carbon Budget, National Grid and UK Energy Research Centre), in common with most UK energy scenario frameworks, have a strong emphasis on quantitative modelling. Therefore, the Challenging Lock-in through Urban Energy Systems project (CLUES) (Sherriff and Turcu, 2012) was also selected to provide examples of predominantly qualitative and narrative scenarios. This work retains an energy policy link (and hence fulfils the primary selection criterion) as it grew out of a UK Government Office for Science 'Foresight' project that took a more exploratory approach in considering the future of energy and the built environment. The final set of energy scenarios selected was that produced by the RSPB (Roddis et al., 2016), which had the specific aim to consider energy deployment from the environmental perspective (connecting to the advocacy objectives of the organisation), and hence potentially provided particular insight on using scenarios to link energy and environmental objectives. Again, a connection to energy policy was maintained through the use within this scenario set of the 2050 Pathways Calculator tool, developed by the UK Department for Energy and Climate Change.

\subsection{Analysis of the scenarios}

Within the scenario sets, a mixture of qualitative and quantitative information was used to describe the scenarios, with quantified parameters reported in different metrics and units. In order to accommodate this range of information types, a qualitative content analysis approach was taken (e.g. Stemler, 2001). Each scenario set document was reviewed and pertinent words and sections of the text within it were attributed to different themes. These themes were not determined a priori, but instead emerged during the review process.

The documents detailing the energy and environmental scenarios contained a vast amount of narrative and quantitative information. In order to avoid including extensive analysis of topics that were exclusive to energy or environment scenario sets (rather than having any overlap between them), an initial analysis step was taken to identify the broad themes that were common to both types of 
scenario set. The energy-related themes for this comparative analysis were therefore determined based on the content of the environmental scenarios, while the environment-related themes were defined by the energy scenarios. The absence of certain key themes that could perhaps be expected to span both types of scenario set (and hence indicated significant gaps) were identified at this stage.

Within the broad themes, individual subthemes were then identified. These subthemes were not subject to the constraint of being common to both energy and environmental scenario sets, and thus the analysis was used to highlight the extent to which treatment of the broad themes was consistent from the energy and environmental perspectives. In the absence of consistent quantified information across all scenarios, it was also necessary to create indicative categorical scales (high, medium, low) to capture the relative magnitude of certain attributes (such as the level of deployment of energy technologies) to allow this information to be compared between scenarios.

\section{Results}

\subsection{Scenario types}

Within the eight scenario sets, 56 individual scenarios were identified (of which 18 were environmental) with between two and 17 scenarios in each set (Table 1). Two approaches were used in deriving the scenario characteristics. The first was a matrix-type approach, in which the characterisation of the future societies tended to reflect increasing divergence between alternative world views based on, for example, the strength of market influence or the varying role of local, national and international governance. These approaches are based on the 'intuitive logics' method developed by Wack (1985) in which a 2x2 matrix is used to identify the key distinctions between individual scenarios (Figure 1). However, the scenario sets reviewed that used a matrix-type approach did not strictly follow this method, and did not limit the scenario options to just two states of two possible attributes. 


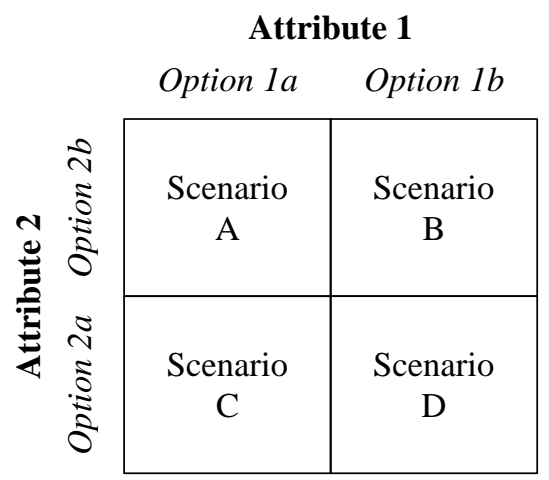

Figure 1. The generic foundation of a matrix approach to scenario development

The differences between the scenarios in these matrix-type approaches resulted from different societal drivers, of which seven main categories emerged from the analysis (Table 2). The second approach to scenario construction followed a more modular structure, involving a core scenario and variants. In these cases, there was not an overarching world view driving the scenario outcomes. Instead, adjustments were made to certain aspects of a core scenario in order to i) consider implications of that pathway extended further into the future (referred to as 'increased timeframe' in Table 2) or ii) to alter underlying assumptions to consider different pathways to achieving a similar outcome, or assess the risks if the future did not unfold as predicted within the core scenario ('sensitivity testing').

Table 2. The proportion of energy and environmental scenarios described by each overarching societal driver and applying different adjustments to the central scenario

\begin{tabular}{|c|c|c|c|c|c|}
\hline \multirow[b]{3}{*}{ Category } & \multirow[b]{3}{*}{ Description } & \multicolumn{4}{|c|}{ Proportion of scenarios } \\
\hline & & \multicolumn{2}{|c|}{ Energy } & \multicolumn{2}{|c|}{ Environmental } \\
\hline & & $\%$ & & $\%$ & (n) \\
\hline \multicolumn{6}{|l|}{ Societal drivers } \\
\hline Green ambition & Emphasis on sustainability and environmental protection & 5 & (2) & 15 & (3) \\
\hline Market forces & A strong role of the market and a focus on economic growth & 3 & $(1)$ & 15 & (3) \\
\hline Global connectivity & High international co-operation and retreat of the nation state & 0 & $(0)$ & 20 & (4) \\
\hline Nationalism & Focus on self-sufficiency and self-governance at the national level & 3 & (1) & 10 & (2) \\
\hline Localism & Increased local governance and engaged local communities & 3 & (1) & 15 & (3) \\
\hline Reduced climate action & Climate change is no longer a driving force and targets lapse & 13 & $(5)$ & 0 & $(0)$ \\
\hline Current ambition & The outcome of continuing on the trajectory in place today & 5 & (2) & 5 & (1) \\
\hline \multicolumn{6}{|c|}{ Core and variant approach } \\
\hline Increased timeframe & Considering the same society further in the future & 10 & (4) & 20 & (4) \\
\hline Sensitivity testing & Assessing the implications if a key assumption is altered & 59 & (23) & 0 & (0) \\
\hline
\end{tabular}


This categorisation of the scenarios, between matrix and core/variant approaches, highlighted the first major difference between the environmental and energy scenario sets, as the former took an exclusively matrix-type approach. Whilst this technique was also applied within the energy scenario sets, these made much more extensive use of the core and variant approach, particularly as a means of sensitivity testing.

A further distinction was that energy scenarios commonly considered the implications of less ambitious emissions reduction targets, whilst this was not a driver of any the environmental scenarios. That is not to say that policy responses to climate change did not feature in any of the environmental scenarios, but that this issue was not the main focus in shaping any of their narratives. There was a relatively small number of examples of energy scenarios that had other societal drivers at their core, which emphasises the centrality of decarbonisation concerns in energy scenarios over the past decade. Conversely, the societal factors that drove environmental scenarios were quite evenly distributed across the main categories described in Table 2 .

\subsection{Themes emerging from the scenario sets}

Seven main themes emerged from the scenario sets (Table 3). These themes (and subthemes within them) related to different attributes of energy supply and demand such as electricity generation and transport, but also to land cover types and usage, which captured wider issues that may affect carbon dioxide emissions and their mitigation. A further theme encapsulated how the scenarios characterised society more broadly. A greater proportion of environmental scenarios contained content relevant to each of the themes (i.e. environmental scenarios tended to broader coverage of common themes), while the energy scenarios focused more narrowly on a smaller number of themes, especially energy supply and transport (Table 3). 
Table 3. The percentage of energy and environmental scenario sets and individual scenarios that included content for the different themes

\begin{tabular}{|c|c|c|c|c|c|c|c|c|}
\hline \multirow[b]{3}{*}{ Theme } & \multicolumn{4}{|c|}{ Scenario set } & \multicolumn{4}{|c|}{ Individual scenarios } \\
\hline & \multicolumn{2}{|c|}{ Energy } & \multicolumn{2}{|c|}{ Environmental } & \multicolumn{2}{|c|}{ Energy } & \multicolumn{2}{|c|}{ Environmental } \\
\hline & $\%$ & (n) & $\%$ & (n) & $\%$ & (n) & $\%$ & (n) \\
\hline Energy supply & 100 & (5) & 100 & (3) & 89 & (34) & 78 & (14) \\
\hline Agriculture and land use & 20 & (1) & 100 & (3) & 8 & (3) & 100 & (18) \\
\hline Household demand & 80 & (4) & 100 & (3) & 21 & $(8)$ & 78 & (14) \\
\hline Transport & 100 & (5) & 100 & (3) & 63 & (24) & 100 & (18) \\
\hline Societal characteristics & 80 & (4) & 100 & (3) & 24 & (9) & 100 & (18) \\
\hline Environmental controls & 40 & (2) & 100 & (3) & 13 & (5) & 72 & (13) \\
\hline
\end{tabular}

As described in Section 2.2, only themes that crossed both energy and environmental scenario sets were subject to detailed analysis. The absence of energy demand by industry (which was not considered in the environmental scenarios) and the restriction of land use and agriculture to farmland, woodland and peat habitats (in line with the limited scope of energy scenarios) identifies two major areas of divergence between the two types of scenarios.

\subsubsection{Energy supply}

In general, the energy scenarios presented quantitative information for energy supply, while the environmental scenarios took a qualitative approach. There were broad similarities between energy and environmental scenarios in terms of the frequency with which reference was made to the main techniques for electricity generation (Figure 2). The most striking difference was that less than $30 \%$ of environmental scenarios mentioned the role of natural gas, while nearly $80 \%$ of energy scenarios did so. However, as there was no explicit reference to gas, it was not possible to determine whether this absence from the environmental scenarios was due to a belief that gas would not form part of the future energy mix or whether a 'business as usual' approach to gas was expected, which, in the absence of major change, did not warrant specific mention. Other differences were that reference to hydroelectric generation was also missing from environmental scenarios, and a much greater proportion of environmental scenarios mentioned wave energy compared to the energy scenarios. 


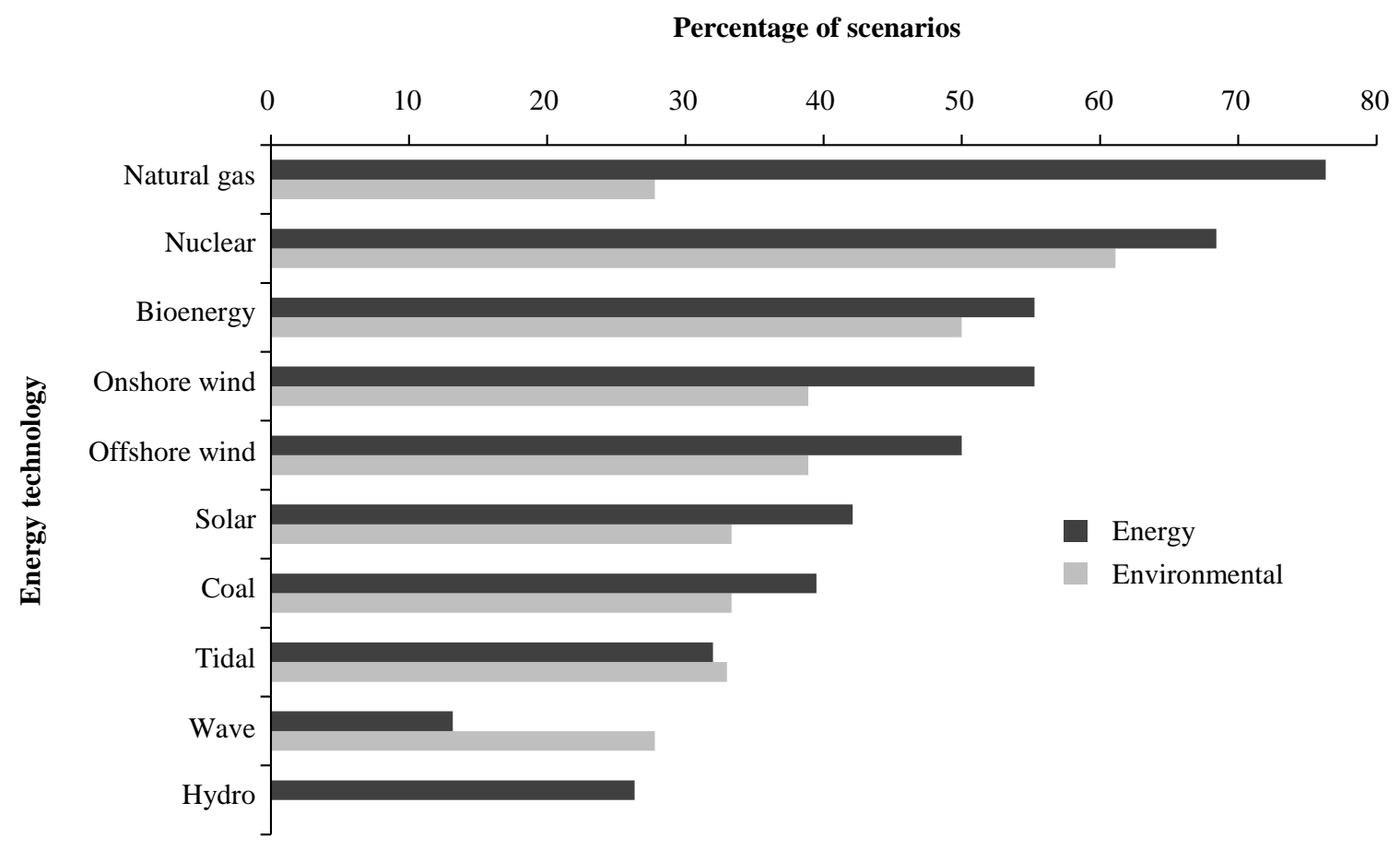

Figure 2. The percentage of energy and environmental scenarios making reference to particular energy supply technologies

Strategies for supplying heat (such as district heating, electrification, and combined heat and power) as well as infrastructure changes for energy supply more broadly (e.g. carbon capture and storage and international grids) were mentioned by only a minority of environmental scenarios, despite being relatively common in energy scenarios. Some technologies and techniques appeared in only a single (or, in one instance, two) scenarios, for example nuclear fusion (Natural England) and hydrogen as a significant energy carrier (UKCIP) were suggested by environmental scenarios, while the use of shale gas extraction (National Grid), extensive floating wind (RSPB) and geothermal energy (RSPB) were outliers suggested by the energy scenarios.

The context in which reference to energy supply technologies was made varied between scenarios. Therefore, the references were categorised according to whether the scenario proposed a low, moderate or high level of deployment of each technology. The category of "none" was also included, to take account of when scenarios explicitly mentioned the cessation of coal-fired or nuclear power. 
This demonstrated that environmental scenarios tend to be more optimistic about the contribution of renewable technologies such as solar, wave, tidal and onshore wind as well as bioenergy, but also more often expect coal to make a significant contribution to energy supply in the future (Figure 3).

\section{a. Energy scenarios}

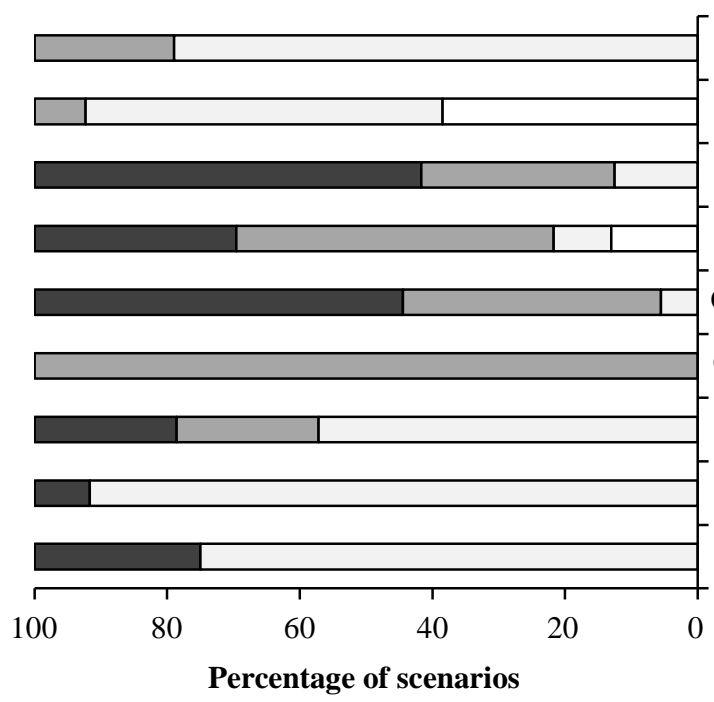

Level of deployment:

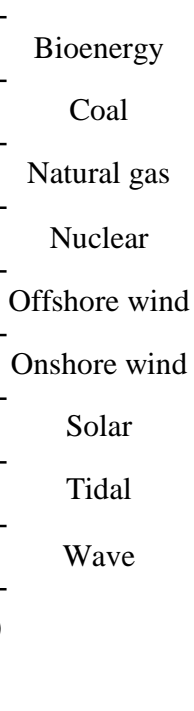

None

\section{b. Environmental scenarios}

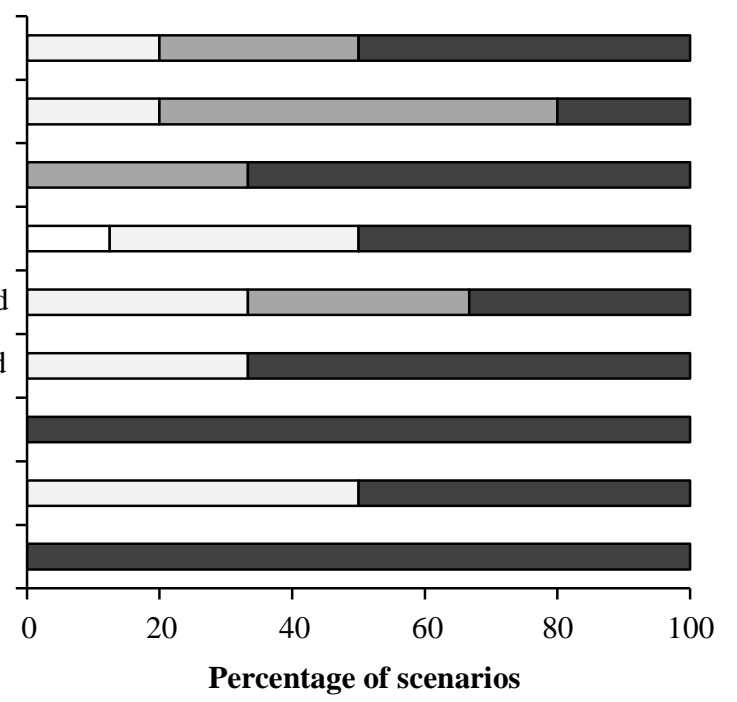

Low $\square$ Moderate $\square$ High

Figure 3. The percentage of energy and environmental scenarios making reference to specific levels of deployment of particular energy supply technologies

There was no evidence that the increased range of societal drivers considered by environmental scenarios led to suggestions for energy futures that had a greater diversity of electricity supply options. Energy scenario sets derived from the same source shared common elements and some levels of energy supply were dominant across the individual energy scenarios (for example, moderate deployment of onshore wind featured in $64 \%$ of energy scenarios, and a high contribution by natural gas in 46\%). However, across all scenarios, there were 27 combinations of technologies types and deployment levels, of which 24 featured in energy scenarios and 17 in environment scenarios, suggesting that while the environmental scenarios introduced some unique combinations, the range of energy scenarios had already introduced diversity of electricity supply options. Detailed investigation of the influence of specific societal drivers on energy supply was not possible due to small sample sizes. 


\subsubsection{Agriculture and Land Use}

Changes to agricultural practices and land use cover were discussed by all the environmental scenario sets, but among energy scenarios was within the scope of only the Fifth Carbon Budget scenario set, reflecting the statutory remit of the Committee on Climate Change to consider all greenhouse gas emissions. The other energy scenario sets were concerned only with the energy system. The relatively small number of scenarios considering this topic prevented any quantitative comparison between scenario types. The vast majority (89\%) of scenarios which did consider the issue expected the area of UK farmland to decrease in future, and a similar proportion (79\%) expected an increase in woodland cover. For both farmland and woodland, the relative change was generally expected to be $5 \%$ or less of the existing area under this land use type.

These changes were usually discussed in terms of general changes in land use practice, rather than making specific reference to how the expansion of energy would affect land use. The UKNEA, however, did make reference to the replacement of grasslands with biofuels and the management of woodland for fuel. Of the other sub-themes that emerged from broader discussions of agriculture and land use changes, the most common were expectations that the quantity of livestock would be reduced (in response to a reduced demand for meat products) while novel crops (particularly high protein grains as well as fungi) would increase.

\subsubsection{Household energy demand}

Within household energy demand, improvements in energy efficiency featured prominently in both the energy and environment scenarios, as did the increased insulation of properties. Beyond these, there was a divergence in the foci of energy and environmental scenarios: the former considered specific energy issues (e.g. temperature preference and the electrification of cooking), while environmental scenarios discussed wider issues related to broader social changes such as urban redevelopment, overall housing demand and occupancy rates. As with agriculture and land use issues, the relatively small number of scenarios addressing this issue prevented any quantitative comparison between scenario types. 


\subsubsection{Transport}

There was considerable heterogeneity in the sub-themes of transport addressed by the scenarios, but a further contrast between the two types of scenario set was apparent: environmental scenarios primarily considered transport choices and behaviour, while energy scenarios had a greater focus on fuel types. For example, $67 \%$ of environmental scenarios anticipated an increased use of public transport, but this was discussed by only $16 \%$ of energy scenarios (Figure 4 ). Conversely, no environmental scenarios made reference to the possibility of public transport being electric or to the use of natural gas as a fuel for heavy transport vehicles. There was closer agreement between the two scenario sets with respect to the use of electric cars and increased rates of cycling, although these were mentioned by only a minority of both energy and environmental scenarios.

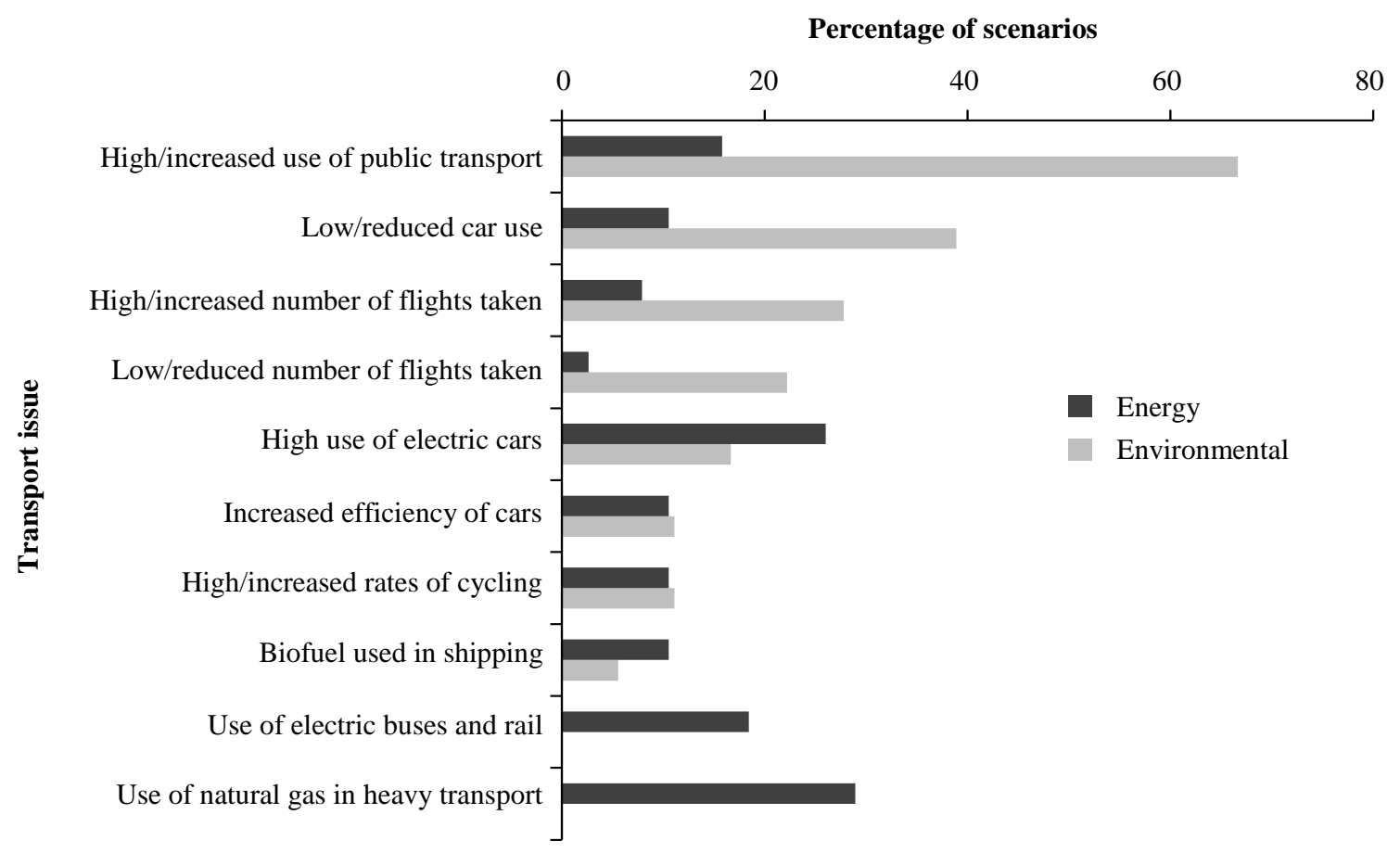

Figure 4. The percentage of energy and environmental scenarios making reference to particular transport issues

As was the case with energy supply technologies, there were certain outlying transport issues or innovations that were rarely discussed in either type of scenarios. The Fifth Carbon Budget considered 
possibilities for hydrogen as a fuel for cars, buses and heavy goods transport, while the National Grid scenarios foresaw its potential only for the latter. Again, illustrating the focus of environmental scenarios on behaviour change, one scenario in the UK NEA assumed road pricing schemes would be common, and a Natural England scenario predicted digital management to optimise local travel.

\subsubsection{Societal Characteristics}

There was a stark contrast between energy and environmental scenarios in how they considered the wider characteristics of future societies. Fifteen main sub-themes were identified, all of which had the potential to have a bearing on energy issues (Figure 5). They described factors such as economic growth, population size and other demographic factors, governance structures, consumer behaviour, and the strength of environmental drivers. At least three environmental scenarios considered each subtheme, but energy scenarios made reference to only six sub-themes. Of these, only GDP/economic growth and population size were considered by more than four (of 38) energy scenarios.

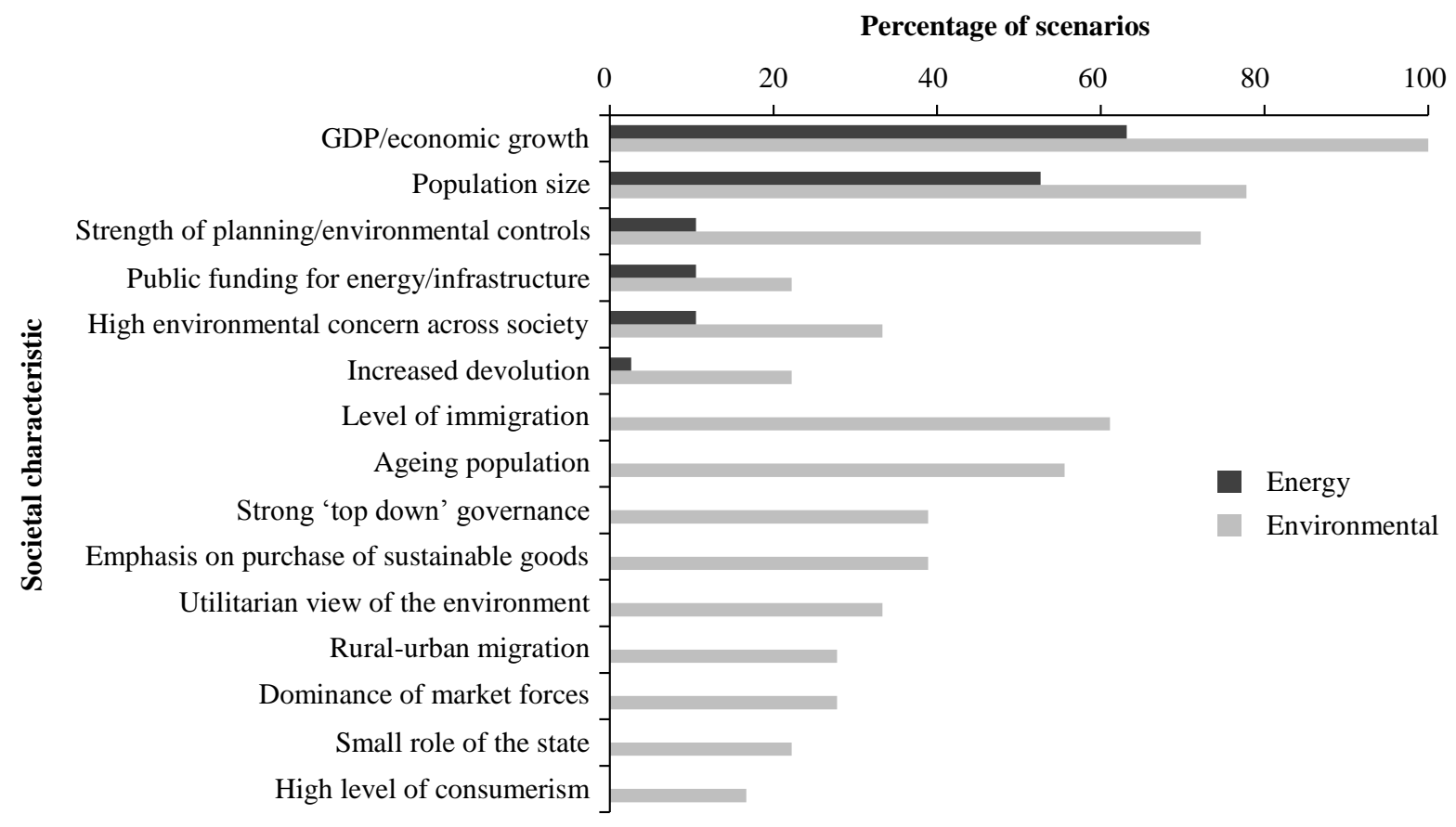

Figure 5. The percentage of energy and environmental scenarios making reference to particular societal characteristics 
While it was relatively common for energy scenarios to consider annual GDP growth rates and the size of the UK population for the 2020s/2030s timeframe, these factors were confined to relatively narrow ranges: annual GDP growth rates were predicted to be between $1.9 \%$ and $2.4 \%$, and the UK population was expected to grow by between 7.3 and 8.0 million. The environmental scenarios considered these parameters for both their 2020s and 2050-2060 cases. In these scenarios, GDP growth was between $1.25 \%$ and $3.0 \%$ for the 2020 s, and as low as $0.5 \%$ for $2050-2060$. Estimates for the UK population size ranged from fall of 4 million people (2020s) to an increase of 14 million people (2050-2060s).

\subsubsection{Environmental controls on development of energy systems}

Planning and environmental regulations are relevant to the development of energy systems as they relate to the degree of environmental impact that will be considered acceptable, and hence how developments might proceed through the consents process. However, environmental controls were mentioned within only one energy scenario set (National Grid). The scenarios focused primarily on stricter controls for onshore oil and gas in the future, but it was also suggested within one scenario (of reduced ambition for low-carbon and energy innovation), that the current environmental legislation will begin to impact on the sources of generation in the short term.

In contrast, discussion of environmental controls featured regularly within environmental scenario sets, across scenarios with different societal drivers. For example, explicit reference was made to new wind, wave and tidal developments being permitted only after passing stringent Environmental Impact Assessments (UK NEA), and to the need for minimal environmental impact being inherent within the design of energy systems (Natural England). Environmental scenarios also considered the implications of environmental controls being weakened by, for example, a drive for economic development (UKCIP) or unregulated growth of the energy sector (Natural England). 


\subsection{Environmental impacts of energy systems}

In general, the environmental consequences of the proposed energy pathways (beyond those related to greenhouse gas mitigation) were not discussed within the energy scenarios, and hence do not feature explicitly as a theme within our analysis. The exception was the RSPB scenario set, the rationale of which was to propose energy systems in which negative impacts on sensitive species and habitats were minimised while still meeting existing carbon emissions reduction targets. This scenario set considered the ecological impacts of particular technologies (e.g. habitat loss, collision risk) and determined a deployment potential to ensure the ecological risk remained low. The DECC 2050 Pathways Calculator was then used to develop three scenarios that met this criterion.

In order to examine how these environmental constraints affected energy supply outcomes, the three RSPB scenarios were compared with a further 17 energy scenarios (within the Fifth Carbon Budget, CLUES, and National Grid scenario sets), selected because they all quantified energy supply in the same unit (TWh; Figure 6). The RSPB scenarios propose more bioenergy, solar, and wind energy offshore wind in particular is much more important within the RSPB scenarios. As has been mentioned previously, floating offshore wind and geothermal energy were unique to the RSPB scenario set. Nuclear energy was not considered in the RSPB framework, as the focus of that scenario set was specifically on renewable energy alternatives to fossil fuels. The other energy scenarios (those not produced by the RSPB) also included two examples where nuclear provided less than 10TWh per year. Abated natural gas (i.e. with carbon capture and storage) was included in the RSPB scenarios, but it was not quantified separately from biogas within the supply associated with carbon capture and storage. 


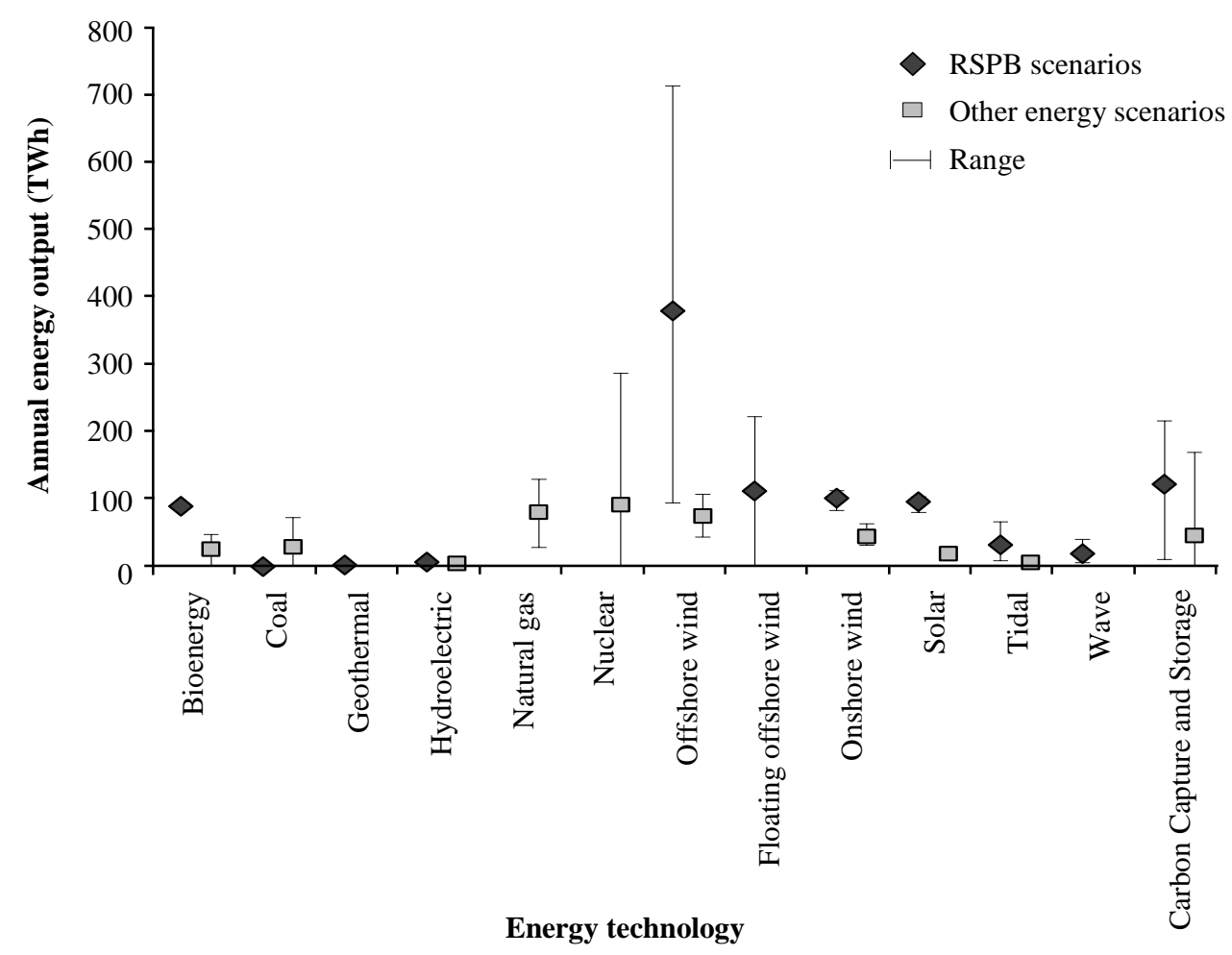

Figure 6. The average, and range of, annual energy output (TWh) for different energy technologies for i) the RSPB scenario set and ii) other energy scenarios (from the 5th Carbon Budget, CLUES and National Grid sets)

\section{Discussion}

It is important to note that the scenarios reviewed had a wide range of aims, from seeking specific, cost-optimised energy outcomes to exploring, in general terms, the environmental challenges that might result from different futures. The purpose of this discussion is not to suggest that individual scenarios were inadequate if they failed to address issues that were beyond their scope. Instead, we seek to explore the lessons that can be learned from the synergies and contrasts between the different sets of energy and environmental scenarios, in order to support the development of future energy scenarios.

Broadly, both energy and environmental scenarios explore 'positive' futures, with continued prosperity and a range of energy options available. While a downgrading of the importance of climate change and a failure to meet carbon targets were considered as elements of individual scenarios, none of the scenario sets employed dystopian thinking (Hjerpe and Linnér, 2009) to propose failed future 
societies. It has been construed as a weakness of scenarios if they assume that society will be much the same in future (McDowall et al., 2014; UK Climate Impacts Programme, 2001), while scenarios that are too radical may be perceived as improbable and therefore less credible. Also, when scenarios are being used to assess public policy questions, there is little value in speculating about a radical change that does not connect to actions that can be taken today (Hughes, 2013). The perception of what constitutes 'radical' is also a shifting baseline: societal world views with a national security theme would be considered more mainstream following recent political changes than would have been the case when, for example, the UK NEA scenarios were described in 2011.

\subsection{Quantitative vs. qualitative approaches}

A significant contrast between the energy and environment scenarios is the prevalence of quantified approaches within energy scenarios, while environmental scenario sets took a more qualitative approach. This is likely to be a reflection of the more focused aims of energy scenarios compared with the broader, exploratory themes of the environmental scenario sets. However, the availability of tools with which to provide quantified outcomes is also likely to be a key factor in the different approaches. The MARKAL model was developed in the 1980s (Loulou and Labriet, 2008) and, with its successor (TIMES), has been used for over a decade within major exercises for projecting UK energy futures in both academic and policy contexts (Ekins et al., 2013). Within the environmental scenario sets, quantified estimates of land cover change were made in the UK NEA, but the implications of the scenarios for certain ecosystem services (such as pollination and air quality) could only be indicated by a probable direction of change, reflecting the absence of similar detailed empirical modelling tools for making quantified predictions of certain environmental changes.

A qualitative assessment of socio-economic characteristics is generally difficult to reconcile with the quantitative approach taken by most energy scenarios. Attempts have been made to quantify socioeconomic variables and incorporate these within energy systems models as a means of assessing the risks and uncertainties around energy outcomes (Chilvers et al., 2017; Eyre et al., 2011), although only a limited set of variables have so far been included in these processes. 
The transition matrices used within the UK NEA are a further an example of how such a process of quantification could be undertaken. These matrices allowed some qualitative assumptions on land use change to be quantified while maintaining the internal consistency of scenario. Integrated assessment models (IAMs) also present an opportunity to assess the interactions between human systems and the wider environment (Moss et al., 2010). To date, IAMs have been most commonly applied in the context of climate change and its mitigation (Harfoot et al., 2014), but have also been used to investigate the implications of other policy alternatives, such as exploring the trade-offs in achieving broader sustainability objectives (van Vuuren et al., 2015). However, IAMs also have their limitations, not least the need for modellers to make choices about how the modelled system represents elements and processes about which our knowledge may be incomplete, and the assumptions made during this process are not always transparent (Beck and Krueger, 2016).

The quantification of societal parameters may be desirable from the perspective of facilitating their explicit evaluation within energy system models, but a limitation of this approach is that the inherent complexity of the socio-cultural context will by necessity be reduced to fit the model structure.

Techniques that permit a looser coupling between narrative and quantitative scenario components have been suggested as an alternative approach (McDowall, 2014).

\subsection{Economic growth and population size}

Economic growth and population size (both easily quantified) were the socio-economic factors most commonly considered by energy scenarios, reflecting that they are used to drive energy demand in models such as TIMES (Loulou and Labriet, 2008) and have a material impact on the outcome of estimations (DECC, 2015). In terms of economic growth, the energy scenarios assume a range of $1.9 \%$ to $2.4 \%$, which could be considered reasonable for the $2020 \mathrm{~s} / 2030 \mathrm{~s}$, given that on average the UK economy has grown by $2.2 \%$ per year since 1980 (ONS, 2016a). However, this trend may not continue: average growth over the past 10 years was only $1.2 \%$, and the past decade included periods of recession (ONS, 2016a), with similar patterns in other developed economies (World Bank, 2016). 
A broader range for GDP, such as that considered by environmental scenarios, and ideally consideration of economic stagnation or even prolonged recession would perhaps make assessments of economic uncertainty more robust.

Similarly, the environmental scenarios suggested a wider variation in the future size of the UK population than did the energy scenarios. The population projections used by the energy scenarios were based on UK Government data, but these are not infallible. For example, in 2000, it was predicted that UK population in 2011 would be nearly 62 million, underestimating the actual figure by 1.3 million people (GAD, 2002; ONS, 2016b). The differences in the underlying assumptions for population trends are compounded the further the projection goes into the future: there is a difference of 12.4 million people in predictions made in 2000 and 2014 for the expected UK population in 2051 (GAD, 2002; ONS, 2016b). Therefore, the narrow range used by the energy scenarios may not be suitably robust.

The energy scenarios reviewed all assumed that the UK population will grow, and this does reflect recent trends. However, there have been periods within living memory during which the UK population did not grow significantly: the decade from 1974 to 1983 was characterised by very small increases and even periods of population decline (ONS, 2016b). This base assumption of population growth perhaps represents a 'precautionary principle', as a larger population may equate to greater challenges in meeting climate targets and providing infrastructure. Long term scenarios should nonetheless also consider the implications of a static or declining population, as incorrect assumptions of future demand may result in the commissioning of unnecessary infrastructure, with associated present costs. Eyre and Baruah (2015), for example, illustrate the significant effect different assumptions on population growth have on projections for gas and electricity demand.

\subsection{Incorporating wider societal characteristics}

Economic growth and population size are just two issues that affect energy outcomes, and it is important that a wide range of factors that might cause uncertainty are considered. Focussing only on 
the same few parametric uncertainties (such as those that are most easily considered within modelling frameworks) risks making the assumption (or arriving at the conclusion) that these are the more important than the structural uncertainty of the wider scenario, which may not be the case (McDowall et al., 2014). The energy scenario sets acknowledge the importance of policy drivers and public behaviour in achieving goals such as demand reduction (Committee on Climate Change, 2015b), but they rarely consider specifically those drivers and behaviours and the impact they may have on the likelihood of proposed outcomes being realised.

This was particularly apparent in the treatment of two themes (household demand and transport), for which the scope of the energy scenarios was mainly to consider specific technological adaptations, while the environmental scenario sets more often focused towards social and behaviour changes. The focus of the energy scenarios on technological issues is of some concern, as wider behaviours will affect energy demand and their omission may have a significant bearing on the robustness of results. There are many uncertainties in domestic heat demand, including the most basic factors of population growth and household size as well as comfort preferences, insulation levels, and penetration rates, which in turn are affected by a range of variables including technical change, prices, social norms, skills and supply chain capacity Eyre and Baruah (2015).

This illustrates why understanding socio-economic issues remains fundamental to the success of energy policies. Public attitudes have been identified as one of the most important systemic uncertainties that will affect the successful achievement of UK energy policy, added to which the aspects of the energy system considered important by the Government and its advisory bodies do not necessarily match the values held by the wider public (Watson et al., 2014). It may be the case that behaviour change is implicit within energy models, the inputs to which may include assumptions on the adoption of new technologies or real-time patterns of demand. However, failure to make these assumptions explicit affects subsequent interpretation and comparison of model outcomes. McDowall (McDowall, 2014) has already shown that using narrative storylines to "ask questions" of transition pathway models can reveal assumptions that would otherwise have remained opaque. 


\subsection{Scenario development}

The environmental scenarios provided a much richer perspective, in socio-economic terms, on the characteristics of future societies, which could provide a further lesson for the development of energy pathways. However, the additional information provided in the environmental scenarios is potentially a result of their more narrative approach rather than their specific environmental focus, and may also stem from the matrix construction that enables the contrasts in societal characteristics to be readily accentuated. This matrix formation stems from the story and simulation approach, which has become the dominant method for environmental scenarios and has been used in high-profile global assessments including the UNEP Global Environmental Outlook, Millennium Ecosystem Assessment and by the Intergovernmental Panel on Climate Change (Roundsevell and Metzger, 2010).

Energy scenarios typically examine how a specific end-point (such as a reduction in carbon emissions by a fixed percentage) could be reached, for a system which, though complex, is understood as bounded and manageable in terms of its physical, temporal and operational structure. Environmental scenarios do adopt techniques including back-casting to consider pathways from the current position to achieving a desired future outcome, but it is more often the case that the storylines are used to explore the environmental response to human activities or the necessary societal adaptations to environmental change (Roundsevell and Metzger, 2010). This difference in the framing of the issue to be addressed is also likely to be a factor in the types of scenario used in the two sectors.

It is not necessarily the case that more explicit consideration of societal drivers requires energy scenarios to adopt the matrix-type approach but the existing modular scenarios could be enriched by considering a broader suite of socio-economic characteristics. At present, alternative pathways in energy scenarios compare attributes such as the presence/absence of nuclear power or the success/failure in meeting emissions reduction targets. Socio-economic characteristics could similarly be expressed in terms of alternative states or options to allow their inclusion. Tools already exist within quantitative modelling for the capturing the variance of one or more parameters through large numbers of model runs, as was undertaken during the development of the UKERC Gas scenarios. 
There is also the potential to extend the modular approach into a more formal morphological analysis (Amer et al., 2013; Bishop et al., 2007), in which the attributes, their alternative states and the combinations selected for each scenario are clearly identified. This would have the advantage of making underlying assumptions more explicit than is perhaps the case at present.

\subsection{Addressing environmental impact}

While scenarios are not intended to produce accurate predictions of the future, some of the scenario sets reviewed (particularly the Fifth Carbon Budget and National Grid) have a direct influence on the formation of UK energy policy and related investment strategies. The approach taken by these scenarios has a tendency to consider the energy sector issue in isolation from the broader policy and management drivers (such as environmental and local government policy). Land use is generally beyond the remit of energy scenarios (except where these consider greenhouse gas emissions more broadly), but the land take of different energy options varies considerably (Cheng and Hammond, 2017). Even within energy options that are grouped under broad categories such as "bioenergy" the land use requirements and wider environmental and social implications vary with different crops. Also, the complex issues around the uptake and sustainability of biomass energy options include potentially lower economic returns compared to other crops, reducing its attractiveness to land owners, as well as the environmental issues surrounding the conversion of grassland to biofuels (Thornley et al., 2009). Consideration of these issues during scenario development would therefore be beneficial, to avoid proposals for energy pathways that are difficult to implement in practice or which call into question the assumptions used by the energy models. Söderholm et al. (2011) for example, consider that expectations of bioenergy and CCS expansion, which play an important role in many global energy models, will lead to intense competition for land in the future.

More broadly, the role of environmental controls on energy system development is rarely considered within energy scenarios, and evaluation of the environmental impacts of energy pathways is almost always lacking. Environmental impact is a key component of the planning framework and hence will affect the likelihood that expected levels of deployment will be possible, as evidenced by, for 
example, the widespread public concerns over fracking (Williams et al., 2015) and the rejection of 57\% of UK onshore wind farm planning applications in 2014 (Tait, 2015). Such failure to incorporate environmental considerations within scenario development has also been noted in a number of reviews of global scale environmental scenarios (Hughes and Strachan, 2010; Söderholm et al., 2011).

The environmental impacts of a proposed pathway can be considered post hoc in a separate process, using tools such as environmental Life Cycle Assessment (e.g. Hammond et al., 2013) ,Alternatively, as was the approach taken by the RSPB, environmental impacts can be incorporated from the outset in terms of constraints on the scenario. The outcomes of the RSPB analysis demonstrate that environmentally preferable solutions may diverge considerably from cost-optimal scenarios, reinforcing the need to explore these issues at an early stage. Howard et al. (2011) report similar findings, with the imposition of socio-environmental constraints resulting in higher costs of energy when compared to a reference scenario designed to meet the UK's emission reduction targets with the lowest impact on welfare.

A key challenge for incorporating environmental factors and outcomes within energy scenarios is that energy pathways are often defined at a national scale, but the environmental impacts will be sitespecific and depend on the location, scale and type of energy intervention. However, the RSPB approach shows that there are methods that allow broad, national-scale environmental assumptions to be integrated into the process of energy scenario development.

The consideration of environmental drivers, constraints and impacts is rarely within the defined objectives of energy scenarios. This requires a change of approach so that the environment is regarded as a fundamental component. Energy pathways already include evaluation of carbon emissions, demonstrating how the scope of scenarios can evolve when environmental policy drivers are sufficiently strong. The recent focus on the water-energy-food nexus may provide a driver to further increase the integration of environmental impacts within energy scenarios. Considering environmental impacts in the context of international agreements and legal obligations (such as in the RSPB 
approach of excluding sites with environmental designations) may be a further mechanism for prioritising those aspects of environmental impact that should be considered fundamental in developing energy pathways.

Recent environmental scenarios have been developed using ecosystem services concepts (e.g the UK NEA as well as the Intergovernmental Science-Policy Platform on Biodiversity and Ecosystem Services; IPBES, 2016). This paradigm may also provide a framework for better integration of environmental issues within energy pathways, as it seeks to place environmental outcomes in terms of human benefit and thus provide a holistic evaluation of impacts on welfare. Where these frameworks include services provided by the abiotic environment, energy itself becomes an ecosystem service and so can be considered in direct parallel with other human benefits of nature. Examples of this approach include incorporating renewable energy within an assessment to prioritise ecosystem service delivery at a regional scale (Casalegno et al., 2014), although it does not yet appear to have been applied specifically in the context of developing energy scenarios.

\subsection{Lessons for Environmental Scenarios}

In the UK, the increasing use of scenarios has been driven by the Climate Change Act (2008), and the need to generate pathways to explore optimum solutions for meeting legally-binding carbon budgets. The lack of any equivalent high-level and time sensitive transition target-setting for the UK's wider environmental system may explain why environmental scenarios are produced less frequently and hence why those available for this analysis were considerably older than the equivalent energy scenarios.

Lessons can be learned from energy pathways for the development of future environmental scenarios, including that environmental scenarios could benefit from a deeper consideration of energy and its implications. It is often difficult for environmental scenarios to impact on policy because policy cycles are short-term, the purpose of the scenarios may not be clear, and their relevance to specific policy outcomes may be limited (Rounsevell and Metzger, 2010). Energy scenarios are often better 
adapted to the policy arena as they address directed policy questions and tend to be produced on a regular (often annual) basis. The greater quantification and use of modelling within energy scenarios could also be an aspiration for environmental scenarios. However, the complexity of environmental systems make this challenging, but there are dangers in presenting policy makers with a reduced picture of this complexity or in choosing a single metric to represent complex issues (Marland et al., 2014; Stirling, 2010).

\subsection{International context}

Our focus on energy and environmental scenarios within a UK context is in part a pragmatic choice a function of our familiarity with policy within this country, and a reflection of strong research and policy drivers across environmental and energy domains. While there are numerous examples of global-scale energy and environmental scenario exercises, these by necessity consider broad global trends illustrated by regional and local examples. As such our focus on the UK reflects the scale at which policy will be implemented.

Examination of national or regional level energy scenarios produced in other countries suggests that the results of the UK analysis are pertinent internationally. A scenario exercise commissioned by the California Energy Commission (Wei et al., 2013), for example, takes a quantitative modelling approach, considers the environment only from the perspective of carbon emissions reductions and land use change, and lacks assessment of social drivers beyond population growth. Similarly, Canada's National Energy Board (2016) takes a core/variant approach, which tests the sensitivity of its baseline projection to transportation, price and market uncertainties. Economic and population growth are considered as key drivers, but no other societal factors are discussed. It is explicitly stated that environmental and socio-economic considerations are generally beyond the scope of the analysis, and the report makes only brief references to, for example, environmental concerns around oil and gas pipelines. 
Other scenarios have gone further in integrating environmental and social drivers. The two matrixtype scenarios within the New Zealand Energy Scenarios (World Energy Council and BusinessNZ Energy Council, 2015) are similar to the UK pathways in that they are quantified using the Global Multi-Regional MARKAL model, have a focus on population, GDP and economic drivers, the environmental emphasis is primarily on decarbonisation and land use change, and evaluation of the environmental impacts of the resulting energy pathways are lacking. However, the broader narratives do delve further into social attitudes and behaviours, including consumer motivation. The wider environmental context in terms of the water-food-energy nexus and the importance of the natural environment for tourism is discussed, as are the critical uncertainties around the scenarios of, amongst others, community acceptance and environmental standards.

\section{Conclusions and Policy Implications}

Although our analysis focused on the UK, there are a number lessons for the development of energy and environmental scenarios in other contexts. The quantitative, focused approach employed by energy scenarios may allow their stated aims such as minimising the costs of tackling climate change to be adequately met, but the paradigm under which these scenarios are constructed is a reflection of a deceptively narrow policy perspective. Where energy scenarios have broader aims (such as to explore how the complex energy landscape is changing), and if the outputs of these scenario exercises are to have a direct bearing on the development and implementation of energy policy or management actions, then lessons can be learned from the review of environmental scenarios. In particular, the range of socio-economic parameters used by recent energy scenarios is perhaps insufficient to ensure that the uncertainty around them is appropriately addressed.

As well as wider environmental interdependencies, social changes and behaviour should be considered more fully alongside technological changes when evaluating alternatives for, for example, transport and household demand. Options for the quantification of broader socio-economic parameters, to facilitate their inclusion in numerical modelling, should also be explored. However, there may be benefit in using the more qualitative approaches for energy scenarios as these provide an 
opportunity for input from a wider number of sectors and stakeholders, and also a more exploratory approach which could lead to a broader spectrum of outcomes. Whether quantitative, qualitative or combined approaches are employed, a more formal process of morphological analysis would increase transparency in the assumptions underlying scenario construction. Finally, to ensure viability of energy scenario outcomes, they would benefit from either a direct inclusion of broader sectors and policies, or alternatively some post hoc analysis of the results in terms of their feasibility within the broader policy and development landscape. Without considering these questions of environmental and socio-economic impacts and sensitivities, there is a risk of proposing energy pathways that are not achievable in practice, or are increasingly ill-matched with the full range of sustainable development policy drivers.

\section{Acknowledgements}

This research formed part of the programme of the UK Energy Research Centre and was supported by the Research Councils UK under the Engineering and Physical Sciences Research Council award EP/L024756/1, with additional support from the NERC-funded ADdressing Valuation of Energy and Nature Together (ADVENT, NE/M019640/1).

\section{References}

Amer, M., Daim, T.U. and Jetter, A. 2013. A review of scenario planning. Futures 46: 23-40

Beck, M. and Krueger, T. 2016. The epistemic, ethical, and political dimensions of uncertainty in integrated assessment modelling. Wiley Interdisciplinary Reviews: Climate Change, 7(5), pp.627-645.

Berntsen, P. B., \& Trutnevyte, E. 2017. Ensuring diversity of national energy scenarios: Bottom-up energy system model with Modeling to Generate Alternatives. Energy, 126, 886-898. 
BIO by Deloitte, IEEP and CEH (2014) Towards integration of low carbon energy and biodiversity policies. BIO by Deloitte (BIO), Institute for European Environmental Policy (IEEP) and Centre for Ecology \& Hydrology (CEH). Draft final report prepared for Defra, project code WC1012,UK.

Bishop, P., Hines, A. and Collins, T. 2007. The current state of scenario development: an overview of techniques. Foresight 9(1): 5 - 25

Brand, C. 2016. Beyond 'Dieselgate': Implications of unaccounted and future air pollutant emissions and energy use for cars in the United Kingdom. Energy Policy 97: 1-12.

Cairns, R. and Krzywoszynska, A. 2016. Anatomy of a buzzword: The emergence of 'the waterenergy-food nexus' in UK natural resource debates. Environmental Science and Policy 64: 164-170.

Casalegno, S., Bennie, J. J., Inger, R., and Gaston, K. J. 2014. Regional scale prioritisation for key ecosystem services, renewable energy production and urban development. PloS one 9(9): e107822

Cheng, V.K. and Hammond, G.P., 2017. Life-cycle energy densities and land-take requirements of various power generators: A UK perspective. Journal of the Energy Institute 90(2): 201-213.

Chilvers, J., Foxon, T.J., Galloway, S., Hammond, G.P., Infield, D., Leach, M., Pearson, P.J.G., Strachan, N., Strbac, G., and Thomson, M. 2017. 'Realising transition pathways for a more electric, low carbon energy system in the UK: Challenges, insights and opportunities', Proceedings of the Institution of Mechanical Engineers Part A: Journal of Power and Energy 231 (6): 440-477

Committee on Climate Change. 2015a. The Fifth Carbon Budget The next step towards a low-carbon economy. Report Presented to the Secretary of State. November 2015 
Committee on Climate Change. 2015b. Power sector scenarios for the fifth carbon budget. October 2015. Convention on Biological Diversity. COP 10 Decision X/2 Strategic Plan for Biodiversity 2011-2020. (Convention on Biological Diversity., 2012). at <http://www.cbd.int/sp/targets/>

Creedy, J., Doran H., Duffield S., George N., and Kass G.. 2009. England's Natural Environment in 2060-Issues, Implications and Scenarios. Natural England Research Report NERR031

de Grenade, R., House-Peters, L., Scott, C.A., Thapa, B., Mills-Novoa, M., Gerlak, A. and Verbist, K., 2016. The nexus: reconsidering environmental security and adaptive capacity. Current Opinion in Environmental Sustainability, 21, pp.15-21.

DECC. 2011. The Carbon Plan: Delivering Our Low Carbon Future. Department of Energy and Climate Change

DECC. 2014. Delivering UK Energy Investment. July 2014. Department for Energy and Climate Change.

DECC. 2015. Updated energy and emissions projections 2015. Department of Energy and Climate Change. November 2015.

Ekins, P., Keppo I., Skea J., Strachan N., Usher W., and Anandarajah G. 2013. The UK Energy System in 2050: Comparing Low-Carbon, Resilient Scenarios. UK Energy Research Centre, London ETI. 2015. UK Scenarios for a Low Carbon Energy System Transition. Energy Technologies Institute, Loughborough, UK.

Eyre, N. and Baruah, P., 2015. Uncertainties in future energy demand in UK residential heating. Energy Policy, 87, pp.641-653. 
Eyre, N., Anable, J., Brand, C., Layberry, R. and Strachan, N. 2011. The Way We Live From Now On: Lifestyle and Energy Consumption. in Skea J., Ekins P. and Winskel M. (eds.) Energy 2050: Making the Transition to a Secure Low-Carbon System, Earthscan, London, 294-323.

Foresight. 2008. Powering Our Lives: Sustainable Energy Management and the Built Environment. Final Project Report. The Government Office for Science, London

Foxon, T. J., and Pearson, P.J.G. 2013. The UK Low Carbon Energy Transition: Prospects and Challenges. Engineering and Physical Sciences Research Council Realising Transition Pathways Report

GAD. 2002. National Population Projections: 2010-Based. A National Statistics publication prepared by the Government Actuary in consultation with the Registrars General. Series PP2 No.23 London: TSO

Haines-Young, R., Paterson J., Potschin M., Wilson A., and Kass G. 2011. “The UK NEA Scenarios: Development of Storylines and Analysis of Outcomes." Chapter 25 in: The UK National Ecosystem Assessment Technical Report. UNEP-WCMC, Cambridge.

Hammond, G. P., Howard, H. R., \& Jones, C. I. 2013. The energy and environmental implications of UK more electric transition pathways: a whole systems perspective. Energy Policy 52: 103-116.

Harfoot, M., Tittensor, D.P., Newbold, T., McInerny, G., Smith, M.J. and Scharlemann, J.P. 2014. Integrated assessment models for ecologists: the present and the future. Global Ecology and Biogeography 23(2):124-143. 
Hjerpe, M., \& Linnér, B. O. 2009. Utopian and dystopian thought in climate change science and policy. Futures 41(4): 234-245.

HM Government. 2017. Building our Industrial Strategy. Green Paper. January 2017.

Holland, R., Ketsopoulou, I., Beaumont, N., Austen, M., Hooper, T., Gross, R., Heptonstall, P., Watson, J. and Taylor, G. 2016a. How consistent and comparable are ecosystem services and energy system scenarios? UKERC Technology and Policy Assessment. Working paper. April 2016, version 1.2 .

Holland, R. A., Scott K., Hinton E.D. Austen M.C., Barrett J., Beaumont N., Blaber-Wegg T., et al. 2016b. Bridging the Gap between Energy and the Environment. Energy Policy 92: 181-89.

Howard, D., Jay, B., Whitaker, J., Talbot, J., Hughes N. and Winskel M. 2011. Not Just Climate Change: Other Social and Environmental Perspectives in Skea J., Ekins P. and Winskel M. (eds.) Energy 2050: Making the Transition to a Secure Low-Carbon System, Earthscan, London, 294-323.

Hughes, N. 2009. Transition Pathways to a Low Carbon Economy. A Historical Overview of Strategic Scenario Planning. A Joint Working Paper of the UKERC and the EON.UK/EPSRC Transition Pathways Project. May 2009.

Hughes, N. 2013. Towards improving the relevance of scenarios for public policy questions: A proposed methodological framework for policy relevant low carbon scenarios. Technological Forecasting and Social Change 80(4): 687-698

Hughes, N., and Strachan, N. 2010. Methodological review of UK and international low carbon scenarios. Energy Policy 38(10): 6056-6065. https://doi.org/10.1016/j.enpol.2010.05.061 
IPBES. 2016. The methodological assessment report on scenarios and models of biodiversity and ecosystem services. S. Ferrier, K. N. Ninan, P. Leadley, R. Alkemade, L. A. Acosta, H. R. Akcakaya, L. Brotons, W. W. L. Cheung, V. Christensen, K. A. Harhash, J. Kabubo-Mariara, C. Lundquist, M. Obersteiner, H. M. Pereira, G. Peterson, R. Pichs-Madruga, N. Ravindranath, C. Rondinini and B. A. Wintle (eds.). Secretariat of the Intergovernmental Science-Policy Platform on Biodiversity and Ecosystem Services, Bonn, Germany. 348 pages.

Loulou, R. and Labriet, M., 2008. ETSAP-TIAM: the TIMES integrated assessment model Part I: Model structure. Computational Management Science 5(1-2): 7-40.

Marland, G., Cherry, T. L., and Neufeld, H. S. 2014. GDP: No one metric can rule them all. Nature 507(7490): $40-40$.

McDowall W., E. Trutnevyte , J. Tomei and I. Keppo. 2014. UKERC Energy Systems Theme: Reflecting on Scenarios. UKERC Working Paper. UK Energy Research Centre, London, available from: http://www.ukerc.ac.uk/publications/ukerc-energy-systems-theme-reflecting-on-scenarios.html McDowall, W. 2014. Exploring possible transition pathways for hydrogen energy: A hybrid approach using socio-technical scenarios and energy system modelling. Futures 63: 1-14.

McGlade, C., Pye, S., Watson, J., Bradshaw, M., and Ekins, P. 2016. The future role of natural gas in the UK. Report for the UK Energy Research Centre. UKERC/RR/RV/2016/01. February 2016.

MEA. 2005. Millenium Ecosystem Assessment. Ecosystems and human well-being: synthesis. Island, Washington, DC. 
Moss, R.H., Edmonds, J.A., Hibbard, K.A., Manning, M.R., Rose, S.K., Van Vuuren, D.P., Carter, T.R., Emori, S., Kainuma, M., Kram, T. and Meehl, G.A., 2010. The next generation of scenarios for climate change research and assessment. Nature 463(7282): 747-756.

National Energy Board. 2016. Canada’s Energy Future 2016. Energy Supply and Demand Projections to 2040. http://passthrough.fw-notify.net/download/265051/http://www.nebone.gc.ca/nrg/ntgrtd/ftr/2016/2016nrgftr-eng.pdf

National Grid. 2015. Future Energy Scenarios. UK gas and electricity transmission.

Ofgem. 2009. Project Discovery Energy Market Scenarios. Office of Gas and Electricity Markets, London, UK.

ONS. 2016a. Office of National Statistics United Kingdom Economic Accounts time series dataset. Release date 30 June 2016.

https://www.ons.gov.uk/economy/grossdomesticproductgdp/datasets/unitedkingdomeconomicaccount s Accessed 25 July 2016

ONS. 2016b. 2014-based national population projections reference volume 30 March 2016. Office for National Statistics https://www.ons.gov.uk/peoplepopulationandcommunity/populationandmigration/populationprojectio $\mathrm{ns} /$ compendium/nationalpopulationprojections/2014basedreferencevolumeseriespp2/chapter2results20 14basednationalpopulationprojectionsreferencevolume Accessed 25 July 2016

Roddis, P., Morrison, A. and Gove, B. 2016. The RSPB's 2050 energy vision. Meeting the UK's climate targets in harmony with nature. Report prepared for the Royal Society for the Protection of Birds. May 2016. 
Rounsevell, M. D., and Metzger, M. J. 2010. Developing qualitative scenario storylines for environmental change assessment. Wiley Interdisciplinary Reviews: Climate Change 1(4): 606-619.

Sharmina, M., Hoolohan, C., Bows-Larkin, A., Burgess, P.J., Colwill, J., Gilbert, P., Howard, D., Knox, J. and Anderson, K. 2016. A nexus perspective on competing land demands: wider lessons from a UK policy case study. Environmental Science \& Policy 59: 74-84.

Sherriff, G., and C. Turcu. 2012. Energy: Looking to the Future. A Tool for Strategic Planning. Prepared for the CLUES (Challenging Lock-in through Urban Energy Systems) project.

Skea, J., Ekins, P. and Winskel, M. (eds.). 2011. Energy 2050: Making the Transition to a Secure Low-Carbon System, Earthscan, London. ISBN: 978-1-84971-084-8

Skeete, Jean-Paul. 2017. Examining the role of policy design and policy interaction in EU automotive emissions performance gaps. Energy Policy 104: 373-381.

Söderholm, P., Hildingsson, R., Johansson, B., Khan, J., and Wilhelmsson, F. 2011. Governing the transition to low-carbon futures: A critical survey of energy scenarios for 2050. Futures 43(10): 1105-1116. https://doi.org/10.1016/j.futures.2011.07.009

Stemler, S. 2001. An overview of content analysis. Practical assessment, research \& evaluation 7(17): 137-146.

Stirling, A. 2010. Keep it complex. Nature 468(7327):1029-1031.

Tait, C. 2015. Transition by Consent. Meeting Britain's Energy Needs Together. Report for the Fabian Society. 
Thornley, P., Upham, P. and Tomei, J. 2009. Sustainability constraints on UK bioenergy development. Energy Policy 37(12): 5623-5635.

Tran, M., Hall J., Hickford A. J., Nicholls R. J., Alderson D., Barr S., Baruah P., Beavan R., Birkin M., and Blainey S. P. 2014. National Infrastructure Assessment: Analysis of Options for Infrastructure Provision in Great Britain, Interim Results. Environmental Change Institute, University of Oxford.

Trutnevyte, E., McDowall, W., Tomei, J. and Keppo, I. 2016. Energy scenario choices: Insights from a retrospective review of UK energy futures. Renewable and Sustainable Energy Reviews 55: 326337.

UK Climate Impacts Programme. 2001. Socio-Economic Scenarios for Climate Change Impact Assessment: A Guide to Their Use in the UK Climate Impacts Programme. Oxford: UKCIP. United Nations. 2104. The United Nations World Water Development Report 2014. Water and Energy Volume 1. United Nations World Water Assessment Programme. UNESCO, Paris

UK National Ecosystem Assessment. 2011. The UK National Ecosystem Assessment: Synthesis of the Key Findings. UNEP-WCMC, Cambridge.

UNFCC. 2015. United Nations Framework Convention on Climate Change. Conference of the Parties. Twenty-first session Paris, 30 November to 11 December 2015. Adoption of the Paris Agreement. FCCC/CP/2015/L.9/Rev.1

van Vuuren, D.P., Kok, M., Lucas, P.L., Prins, A.G., Alkemade, R., van den Berg, M., Bouwman, L., van der Esch, S., Jeuken, M., Kram, T. and Stehfest, E. 2015. Pathways to achieve a set of ambitious 
global sustainability objectives by 2050: Explorations using the IMAGE integrated assessment model. Technological Forecasting and Social Change 98: 303-323.

Wack, P. 1985. Scenarios: unchartered waters ahead. Harvard Business Review. September-October 1985: 73-89

Watson, J., Gross, R., Ketsopoulou, I. and Winskel, M. 2014. UK Energy Strategies Under Uncertainty - Synthesis Report REF UKERC/RR/FG/2014/002. UKERC, London.

Wei, M., Greenblatt, J., Donovan, S., Nelson, J., Mileva, A., Johnston, J. and Kammen, D. 2013. Scenarios for meeting California's 2050 Climate Goals. California's Carbon Challenge Phase II: Volume I. Energy Research and Development Division Final Project Report Prepared for California Energy Commission.

Williams, L., Macnaghten, P., Davies, R. and Curtis, S. 2015. Framing ‘fracking': Exploring public perceptions of hydraulic fracturing in the United Kingdom. Public Understanding of Science p.0963662515595159.

Winskel, M. 2016. 'From optimisation to diversity: Changing scenarios of UK buildings heating' in D. Hawkey, J. Webb, D. McCrone. H. Lovell and M Winskel Sustainable Urban Energy Systems, pp.68-90, Routledge, London.

World Bank. 2016. GDP growth (annual \%).

http://data.worldbank.org/indicator/NY.GDP.MKTP.KD.ZG Accessed 21 July 2016

World Energy Council and BusinessNZ Energy Council, 2015. New Zealand Energy Scenarios. Navigating energy futures to 2050. http://www.bec.org.nz/_data/assets/pdf_file/0014/110309/BECReport.pdf 